\title{
BALANCES Y DESAFIOS EN URUGUAY LUEGO DE UNA DÉCADA DE GOBIERNO DE LA IZQUIERDA
}

\author{
BALANCE AND CHALLENGES IN URUGUAY AFTER A DECADE OF \\ LEFT GOVERNMENT
}

\author{
Gerardo Caetano \\ Universidad de la República, Montevideo, Uruguay ${ }^{1}$
}

Resumen: En el artículo que sigue se realiza un balance crítico e integral acerca de los principales resultados de los dos gobiernos frenteamplistas desplegados en la última década (2005-2010 y 2010-2015). Asimismo, se registran los principales desafíos que enfrenta desde en un contexto de desaceleración del tercer gobierno de la izquierda presidido por Tabaré Vázquez desde marzo de 2015. En el análisis de esa tensión entre balances y desafíos, el autor procura fundamentar que la coyuntura actual no es la hora del "freno" sino la de un renovado y responsable "impulso" a las políticas transformadoras.

Palabras clave: Uruguay; Frente Amplio; Políticas Públicas.

Abstract: This article proposes a general and critical evaluation of the governments of the Frente Amplio in the last decade. (2005-2010 and 2010-2015) It also identifies the main challenges of the current administration and the context of deceleration of the economy. The author argues that these challenges and critical balances should not mean the stoppage of the reformist project but should be taken as an opportunity to actually go further in such process.

Key words: Uruguay; Frente Amplio; Public Policy.

\footnotetext{
${ }^{1}$ Historiador y politólogo. Coordinador del Observatorio de Coyuntura Política, Instituto de Ciencia Política; director Académico del Centro para la Formación en Integración Regional; Presidente del Consejo Superior de Faculdade Latino-Americana de Ciências Sociais. E-mail: <gcaetano50@gmail.com>. Recebido em: 26.02.2016; aceito em: 07.06.2016.
} 


\section{DEL PAÍS DE LA CRISIS A LA HIPÓTESIS DEL DESARROLLO}

A comienzos de este siglo, el entonces presidente Jorge Batlle (2000-2005) todavía podía marcar la impronta de la política uruguaya con su peculiar estilo, orientado -como él mismo definió- a "desacralizar el poder" y a postular la búsqueda de un nuevo "estado del alma", aunque desde un claro alineamiento fuertemente liberal en materia de política económica e inserción internacional. Sin embargo, con la recesión instalada en la región desde 1999 y con los primeros indicios sobre la inminencia del desplome argentino que se confirmaría en diciembre del 2001, poco a poco comenzaron a resultar cada vez más evidentes las debilidades del gobierno, sustentado, además, en una coalición difícil entre los partidos tradicionales uruguayos (Blanco y Colorado), que Batlle buscó tramitar desde un vínculo directo y osado con la opinión pública. Luego el país comenzó a padecer las llamadas "siete plagas" (aftosa, desequilibrios monetarios con la región, crisis financiera, desacomodamiento de los mercados internacionales, etc.) y más allá de controversias, el presidente Batlle y su gobierno vieron caer a ritmo de vértigo no solo su popularidad sino también su credibilidad gobernante.

El estallido de la crisis, que venía anunciándose pero que finalmente se desató en el país con toda su virulencia en 2002, encontró a un gobierno muy debilitado en varios frentes. Los fundamentos de la reforma constitucional de 1996 - crear reglas electorales que incentivaran coaliciones fuertes y duraderas y presidentes con fuerza política y respaldo propios $-^{2}$ pusieron de manifiesto su dudosa consistencia en aquella encrucijada. La coalición se rompió en el peor momento y el centro presidencial alcanzó en esa misma coyuntura crítica una debilidad tal que lo llevó casi al inmovilismo y a la imposibilidad de interlocución negociadora. Como hoy sabemos y entonces se intuía, no faltaron conspiraciones que buscaron la interrupción del mandato de Batlle y la realización de elecciones anticipadas, hipótesis catastrófica que pudo evitarse gracias a la lealtad institucional y el civismo puestos de manifiesto por la amplia mayoría de los actores políticos y sociales en el país. ${ }^{3}$

A partir de esa dura inflexión de la historia reciente del Uruguay, se iniciaba una larga década y media pródiga en acontecimientos y transformaciones de significación particular. Reseñemos cuatro especialmente relevantes:

a) El país atravesó una de las más profundas crisis económicas y sociales de su historia moderna, solo comparable a las del ajuste recesivo (1982-1984) al final de la dictadura y a la de comienzos de la década de los treinta.

La hondura de la crisis resultó de una magnitud inusitada. La recesión se prolongó prácticamente durante cuatro años y medio, desde enero de 1999 hasta mediados del 2003. Como se advierte en los cuadros y gráficas que se incluyen más adelante, el examen de indicadores como la caída vertical del PIB entre fines de 1998 y mediados de 2003 (en términos globales y por persona), los niveles del desempleo que orillaron la cifra récord del $20 \%$, los problemas de ocupación que afectaron a la mayoría de los activos, la fuerte

\footnotetext{
${ }^{2}$ La reforma constitucional de 1996 básicamente se orientó a reformas del sistema electoral. Entre otras disposiciones, introdujo la segunda vuelta entre los dos candidatos más votados, para el caso de que el candidato ganador en la primera vuelta no obtuviera el $50 \%$ más uno de los votos emitidos. En cuatro ciclo electorales bajo estas reglas (1999, 2004, 2009 y 2014), solo Tabaré Vázquez en el proceso electoral del 2004 pudo ganar en primera vuelta.

${ }^{3}$ A este respecto, cfr. muy especialmente Claudio Paolillo, Con los días contados. Montevideo: Búsqueda - Fin de Siglo, 2004.
} 
reducción del salario real, el aumento de la inflación, la relación entre la deuda pública y el PIB, el descenso también vertical de las exportaciones, la retracción de la industria manufacturera, la profundización del endeudamiento agropecuario, la crisis devastadora del sistema financiero, entre otros procesos, llevaron al país a los umbrales del default. Luego de un agobiante feriado bancario, en aquella semana inolvidable de los saqueos y rumores de finales de julio y comienzos de agosto del 2002, finalmente el gobierno pudo contar con el respaldo directo de un préstamo "puente" otorgado por el gobierno norteamericano, lo que permitió el acuerdo con los organismos financieros internacionales y evitar el temido default. ${ }^{4}$

Quedaban, sin embargo, las terribles secuelas sociales de la crisis. En apenas cuatro años emigraron más de cien mil uruguayos, lo que superaba la brecha entre nacimientos y defunciones durante ese mismo período. Según datos oficiales, la pobreza trepó en 2004 al $39.9 \%$, con seis de cada diez niños de 0 a 5 años en esa condición. La tormenta puso al desnudo, además, las falencias del Estado en la atención a una situación de emergencia social. Estos problemas se pusieron de manifiesto tanto en el diseño de políticas sociales adecuadas, como en el manejo de información coherente y actualizada, o en la consistencia y fortaleza de los servicios educativos y sanitarios en todo el país. Quedaba claro que la "sociedad hiperintegrada" y el "Estado escudo de los débiles", tradicionales del viejo Welfare State uruguayo del "primer batllismo", ${ }^{5}$ habían quedado atrás y que en el país emergían registros antes insospechados de indigencia, desnutrición infantil, radicación territorial del poder social. El avance de la pobreza y de la marginación (esta última con sus connotaciones culturales además de sociales) evidenciaba el cuadro de una sociedad fragmentada, guetizada, con rupturas profundas del tejido social y de los espacios públicos.

b) El país inició, tras esa crisis, uno de los períodos de mayor crecimiento económico de su historia moderna, aún superior al que experimentó entre mediados de los años cuarenta y cincuenta del siglo pasado.

Como se registra en los gráficos correspondientes que aparecen más adelante, desde el segundo semestre del 2003 todos los principales indicadores económicos y sociales evidenciaron una evolución particularmente positiva: fuerte crecimiento del PIB; ascenso sostenido de las inversiones en general y de la inversión extranjera directa en particular; incremento de las exportaciones y de los ingresos vinculados con la industria turística; disminución sensible de la tasa de desempleo y de los índices de pobreza e indigencia (en rigor a partir de 2005); franco aumento del gasto público social per cápita (también desde 2005); gradual disminución de la concentración del ingreso (a partir del 2007). Como se verá más adelante, sobre algunas de estas variables comienzan a evidenciarse señales de desaceleración en el último bienio, pero hasta el momento no se advierten perfiles de retroceso consolidado.

Las consecuencias muy positivas de este crecimiento sostenido que ya lleva trece años, y que incluso, hasta ahora al menos, ha podido sortear con razonable éxito las incertidumbres e impactos de la crisis internacional y regional, no pueden ocultar empero

\footnotetext{
${ }^{4}$ Cfr. al respecto dos visiones diferentes acerca del proceso de la última crisis: Carlos Sténeri, Al borde del abismo. Uruguay y la gran crisis del 2002-2003, Montevideo, EBO, 2011; Carlos Luppi, La historia no oficial de la crisis y una lección pendiente. Montevideo, Sudamericana, 2012.

${ }^{5}$ La referencia al "primer batllismo" apunta a destacar el impulso transformador de José Batlle y Ordóñez (18561929), quien fue Presidente en dos períodos (1903-1907 y 1911-1915) y lideró un movimiento reformador dentro del P. Colorado de enorme gravitación en la historia política del Uruguay contemporáneo.
} 
ciertas interpelaciones que suscitan sus fundamentos. El dinamismo económico ha provenido del auge del precio de los commodities y de la inserción privilegiada del país en sus mercados internacionales. El decisivo incremento de la tasa de inversión ha derivado fundamentalmente de las inversiones extranjeras, con relativo involucramiento del capital nacional. Las exportaciones con valor agregado y perfil industrial no han aumentado en forma significativa y han seguido radicadas fuertemente en la región, tanto en el MERCOSUR como en América del Sur. No han ocurrido transformaciones estructurales en lo que tiene que ver con los contornos de la industria nacional y con los procesos de agregación de valor tecnológico a la producción exportable, más allá de algunos cambios que requerirán de más tiempo para poder hacer plenamente visibles sus efectos. La explosión productiva del sector agropecuario ha puesto de manifiesto un "apagón logístico" que compromete la continuidad del dinamismo económico. En suma, el crecimiento económico del país volvió a depender del viento favorable de los mercados internacionales para nuestros tradicionales rubros de exportación, lo que no deja de generar las interpelaciones del recuerdo de otras "prosperidades frágiles" que el país ya ha vivido en el pasado. Esta perspectiva se ha vuelto más vívida con el impacto más sensible sobre el país de la desaceleración del "auge de los commodities" y las complicaciones de los mercados internacionales del último bienio.

c) El país experimentó el cambio político quizás más importante desde comienzos del siglo pasado: la llegada al gobierno nacional de la izquierda y, consecuentemente, la coincidencia por primera vez de los dos partidos tradicionales en la oposición.

Los resultados electorales verificados en octubre de 2004 y ratificados luego en noviembre de 2009 y noviembre de 2014 han confirmado lo que muchos vaticinaban: ese otro país que en lo social había terminado de consumarse luego de la crisis del 2002, ha tenido finalmente su traducción en el campo político-electoral y en la transformación radical del sistema de partidos. En ese contexto, la izquierda uruguaya, a través del Frente Amplio, ha podido lograr tres gobiernos consecutivos con mayoría legislativa. Este gran éxito electoral, sin embargo, no nació como traducción política de la coyuntura recesiva más reciente, iniciada formalmente en enero de 1999 tras la devaluación del real. Como se advierte con claridad en el Gráfico 01, los cambios electorales reconocen una fragua más dilatada en el tiempo, con un crecimiento sostenido de la izquierda luego de la dictadura civil militar (19731985).

Para explicar las razones de la victoria de la izquierda en las urnas a partir del 2004, en los últimos tiempos se ha multiplicado en los ámbitos político y académico la postulación de razones diversas. En trabajos recientes, diversos autores han manejado un cúmulo de razones más o menos conjugadas y prioritarias: una suerte de determinismo demográfico del crecimiento del caudal electoral de la izquierda, explicado por su consistente mejor llegada a los sectores más jóvenes, urbanos y educados (BUQUET \& ARMAS, 2004; ARMAS, 2009); la cosecha de los dividendos de una creciente tradicionalización y nacionalización del Frente Amplio (LANZARO, 2004), con el consiguiente aumento de su producción simbólica y cultural como factores atractivos del voto; una moderación de sus propuestas ideológicas y programáticas (GARCÉ \& YAFFÉ, 2005; YAFFÉ, 2005), con el correspondiente corrimiento de su convocatoria al centro del electorado; la fuerza carismática de sus liderazgos y su relativa facilidad para renovarlos en los últimos años (lo que no significa una disminución de la edad promedio de su elenco de dirigentes, que actualmente muestra índices notorios de envejecimiento); una mejor y más flexible adaptación a los cambios verificados en el país y en el mundo a diversos niveles de lo que podríamos calificar como la nueva cultura política más al uso; el respaldo tácito de la adhesión genérica a la izquierda proveniente de circuitos 
de socialización todavía muy relevantes en el país (sistema educativo, redes laborales y sindicales, grupos territoriales, etc.); el acierto de las estrategias políticas de corto y mediano plazo implementadas por las fuerzas políticas progresistas, claramente contrastante con cierta "derrota cultural" y un espíritu de derrotismo que comenzó a ganar a los llamados "partidos históricos", en particular durante la década anterior a 2004.

Aunque todas estas razones han sido objeto de debate y no han recibido adhesión unánime, también es cierto que cualquier explicación que tienda a privilegiar en exceso una sola de las causas esgrimidas aparecerá como insuficiente. Fue la conjugación más o menos contemporánea de estos y otros factores lo que explica el crecimiento electoral de la izquierda y cualquier interpretación monocausal pecará de insuficiente. Sin embargo, en lo que sí existe una postulación mayoritaria (aunque también contestada) es en que la mayoría de las razones de la primacía progresiva de las izquierdas en el país hay que buscarlas en el terreno de la competencia política y no fuera del mismo.

d) Con el telón de fondo de estos cambios profundos y de la mano del optimismo social derivado del crecimiento económico sostenido, ha crecido la percepción pública acerca de la posibilidad-por primera vez en muchas décadas-de que el país pueda avanzar hacia un estado de desarrollo cualitativamente diferente.

Como lo indican las mediciones de la última década del Latinobarómetro, la opinión pública en Uruguay parece haber dejado atrás los perfiles de su clásico pesimismo, compitiendo - sin duda que en ancas de la euforia económica - entre las sociedades con mayor "optimismo económico" del continente. Como veremos en la próxima sección, razones y fundamentos empíricos no faltan para sustentar este estado de ánimo. La percepción pública de que el país puede acceder finalmente al registro en varios planos de mediciones propias del mundo desarrollado ha crecido. Ello no solo se observa a nivel del discurso de los gobernantes de turno (por obvias razones, los dirigentes de la oposición son más renuentes a pronunciamientos de este tipo) sino que, como se ha señalado, se encuentra presente en el imaginario colectivo de franjas importantes de la población.

De todos modos, esta novedosa percepción colectiva por contraste vuelve más visibles ciertos desajustes que la bonanza económica no hace sino resaltar. La contradicción entre el crecimiento de la economía y la situación de deterioro que exhiben aspectos claves para una sociedad desarrollada (como son el nivel de cohesión social, los desempeños del sistema educativo o las bases de infraestructura para hacer sustentable la continuidad del despegue productivo, entre otros), interpelan de modo radical toda autocomplacencia en las evaluaciones.

En cualquier hipótesis, lo acontecido en esta última década, que no ha hecho sino profundizar el signo de cambio profundo que caracteriza los últimos 30 años desde el fin de la dictadura, se orienta en la hipótesis sobre una profunda mutación de la democracia uruguaya. Más allá de sus peculiaridades - algunas de ellas intensas - con relación al resto de los sistemas políticos latinoamericanos, también la democracia vernácula participa, a su modo y en sus tiempos, de ese proceso de "cambio político en la fragmentación" que caracteriza la coyuntura actual que vive la gran mayoría de las democracias del continente. Pese a las resistencias de su potente matriz tradicional, la democracia uruguaya no resulta ajena a ese gran "giro de época" que signa las transformaciones profundas en el "hacer" y en el "pensar" la política que se perciben a escala global y regional. 
¿Cuáles podrían ser algunos de los ejes de interpelación más efectivos para el registro de esas nuevas pautas ciudadanas, expresadas en su vigencia incremental por múltiples procesos transcurridos en las últimas tres décadas que han seguido a la dictadura y que aparecen a nuestro juicio ratificadas por el último ciclo electoral 2014-2015? Repasemos algunos factores de los más evidentes, dentro de una lista por cierto más extensa: i) se han sucedido, en los últimos años, cambios profundos en la identidad y en la vida cotidiana de todos los partidos políticos uruguayos, tanto en lo que tiene que ver con sus modelos organizativos como en sus pautas de funcionamiento, sus mapas sectoriales internos, sus propuestas ideológicas y sus comportamientos electorales; ii) del mismo modo, ha ido variando - en forma paulatina, pero sostenida - la ecuación global del sistema de partidos a nivel de sus interrelaciones más generales, la que parece consolidarse en el formato de un esquema bipolar, con el Frente Amplio de un lado y los partidos tradicionales del otro; ${ }^{6}$ iii) la reiteración de la apelación práctica a los instrumentos de democracia directa en el período que siguió al fin de la dictadura ha ido ensanchando el espacio político de los movimientos transpartidarios de participación ciudadana, pese a que ello no ha supuesto -ni supone- el desborde de la persistencia de la centralidad partidaria y del terreno privilegiado del arbitraje de las elecciones nacionales $;^{7}$ iv) han cambiado de manera muy fuerte y visible las condiciones de origen y las modalidades de ejercicio de los liderazgos personales a nivel de los partidos, lo que sin llegar a las magnitudes de otros ejemplos cercanos en el continente, traduce la emergencia de fenómenos realmente inéditos en la historia política uruguaya; v) en particular durante los últimos años del gobierno frenteamplista, pero sin duda como culminación de un proceso anterior, se ha venido consolidando una modificación intensa de los libretos más cotidianos del debate político, con una presencia creciente de los temas de la "seguridad", de la llamada "agenda postmaterialista" y de los "nuevos derechos", con una fuerte referencia a tópicos de moral pública y privada; vi) el peso de los poderes públicos y el funcionamiento habitual del régimen político han ido variando de manera real, con una profundización gradual del formato presidencialista, de todos modos menor a la media verificada en América Latina y con perfiles de moderación; vii) se ha acrecentado de manera visible el peso de nuevas lógicas de opinión y de decisión ciudadanas, en el marco de la vigencia ascendente de circuitos propios de un "ágora mediática" genuina y con perfiles renovados, que nos hablan de un nuevo electorado, con apertura a comportamientos e identificaciones más imprevisibles que los de antaño; viii) aunque de manera aún más lenta que en las dimensiones anteriores, se vienen verificando modificaciones relevantes a nivel de la matriz ideológica dominante en el sistema político, con la aparición de algunos indicios de novedades importantes sobre el particular. ${ }^{8}$

Con su estilo intransferible y polémico, tan a contramano de los cánones tradicionales que hacen a los contornos más aceptados y previsibles del paradigma político uruguayo, la figura del presidente José Mujica (2010-2015) tiende a simbolizar las peculiaridades de la

\footnotetext{
${ }^{6}$ Gustavo De Armas ha afirmado que el Uruguay se orienta hacia un "pluralismo moderado que gira en torno a una nueva dinámica bipolar" (2009, p. 42).

${ }^{7}$ Esto último recibió una nueva confirmación con lo sucedido en octubre de 2009 con relación al fracaso de los plebiscitos por la anulación de la Ley de Caducidad y por el voto de los uruguayos residentes en el exterior, celebrados en forma simultánea con la primera vuelta presidencial y las elecciones legislativas. El que estos últimos comicios hayan primado nítidamente en el interés ciudadano sobre las dos convocatorias plebiscitarias en la visión de muchos analistas afectó la chance de estos últimos.

${ }^{8} \mathrm{La}$ brevedad exigida a este texto nos inhibe de profundizar en torno a este aspecto. Simplemente anotemos sobre este particular la hipótesis acerca de evidencias de cierta caída de los componentes más republicanos en el debate público, de manera especial en el tratamiento de temas vinculados con la "seguridad" y el consumo juvenil de drogas, entre otros.
} 
encrucijada más actual de la política uruguaya. Sin embargo, a nuestro juicio, si se pone solo el foco sobre el fenómeno Mujica ${ }^{9}$ y no se indaga acerca de lo que su encumbramiento expresó y expresa en términos más colectivos e históricos, si no se concentra la atención y el análisis en las transformaciones profundas que han sufrido el modelo y las prácticas predominantes de la ciudadanía en el Uruguay reciente, no se terminará de advertir y de entender qué es realmente lo que pasa. El propio Mujica supo sintetizarlo expresivamente en el discurso inaugural de su presidencia, el $1^{\circ}$ de marzo de 2010 ante la Asamblea General: "No está fácil navegar. Las brújulas ya no están seguras de dónde quedan los puntos cardinales".

\section{ALGUNAS MANIFESTACIONES DE CAMBIO}

Como ya se ha señalado, al registrar las notas más salientes del recorrido reciente del país fácilmente se advierte el marcado crecimiento de su economía. Tras la profunda recesión que Uruguay experimentó entre 1999 y 2002, “coronada" por la crisis de 2002, la economía nacional inició nuevamente una fase de crecimiento sostenido a tasas inéditas para la historia reciente del país. Como se puede apreciar en el Gráfico 02, desde el momento en el que la economía uruguaya retomó la senda del crecimiento hasta el presente, los niveles de crecimiento se ubicaron entre los más significativos de las últimas décadas. Más aún, para hallar en la historia moderna del país una fase similar es necesario retrotraerse a mediados del siglo pasado: solamente entre la primera mitad de los años cuarenta y mediados de los cincuenta es posible advertir un crecimiento acumulado del PIB per cápita similar. Por otra parte, la razonable previsión de crecimiento para los próximos años, aun con la desaceleración iniciada a partir de 2014 , hace pensar que la economía uruguaya muy probablemente acumule durante este período, que se inicia tras la crisis de 2002, el mayor crecimiento de toda su historia moderna.

Si bien el crecimiento que la economía uruguaya ha venido experimentando desde el segundo semestre de 2003 constituye una buena noticia y determina, en gran medida, el cambio profundo que la sociedad uruguaya ha experimentado en otras áreas (en particular, el sostenido descenso de la pobreza y la indigencia), constituye un acto de prudencia observar con atención la trayectoria del país en materia económica en las últimas décadas para evitar una mirada simplista y exitista. Como ha sido señalado recurrentemente (BÉRTOLA \& BITTENCOURT, 2005), la economía uruguaya exhibe desde hace varias décadas un patrón de crecimiento que se caracteriza por la alternancia de períodos expansivos y fases recesivas. ${ }^{10}$ Sin abandonar esa actitud de prudencia al momento de evaluar en la larga duración la novedad o el carácter casi inédito del crecimiento experimentado en los últimos

\footnotetext{
${ }^{9}$ El expresidente José Mujica, contra sus propias expectativas, se ha convertido en los últimos años en lo que algunos analistas han denominado un "Presidente viral" en las redes sociales. Sus discursos en foros internacionales, su estilo de vida austero y campechano, sus posturas ante diferentes temas, las decenas de libros que se han centrado en el análisis de su vida, le han valido un fuerte reconocimiento internacional.

${ }^{10}$ En esta dirección, Bértola y Bittencourt sostienen: "La economía uruguaya mostró, a lo largo del siglo veinte, una tasa de crecimiento económico promedio muy baja, que le hizo perder posiciones en el concierto internacional de manera muy marcada [...] Una de las características más nocivas del crecimiento económico del país ha sido la falta de continuidad. La uruguaya no es una economía estancada e inmóvil. Por el contrario, ha demostrado, de tanto en tanto, que puede experimentar cortos períodos de muy rápido crecimiento. El problema es que no le ha resultado posible mantener estable el ritmo de crecimiento; por el contrario, cada período expansivo culmina con crisis muy profundas que llevan al fracaso de empresas, personas, de instituciones..." (2005, p.305-306).
} 
años, es posible identificar algunos indicios sobre cierta solidez de las bases en las que se asienta dicha expansión, en particular el crecimiento de los niveles de inversión. Como se puede apreciar en los Gráficos 3 y 4, desde 2002 al presente (aunque con una caída entre los años 2008 y 2009) la inversión ha crecido en forma pronunciada en el país, alcanzando en 2008 el nivel más alto de las últimas décadas. Asimismo, la inversión extranjera directa ha crecido en forma significativa, con niveles promédiales altos, pese a los altibajos. ${ }^{11}$

Por cierto, sostener este incremento en los niveles de inversión requiere la implementación de un conjunto de políticas económicas (comercial, fiscal y tributaria) y de políticas destinadas a expandir y mejorar la calidad de la infraestructura, así como de políticas sociales que acrecienten la cohesión social genuina en el país, que generen condiciones materiales favorables e incentivos para los actores. En suma, el crecimiento que ha venido experimentando la economía uruguaya en forma sostenida durante los últimos años $-\mathrm{y}$ que muy probablemente continúe registrándose en los próximos años aunque a tasas menoresdebe constituir, ante todo, una oportunidad histórica - pese a lo solemne del calificativo-para consolidar en algunas dimensiones y sentar en otras los pilares de un desarrollo sostenido y sustentable.

El sostenido crecimiento de la economía, jalonado, entre otros factores, por el incremento de la inversión, se ha traducido en un fuerte descenso del desempleo hasta alcanzar, en los últimos años, los valores más bajos de las últimas décadas. Basta observar el comportamiento de este indicador - tan sensible en la consideración pública y en el debate político- desde fines de 2002 al presente (Gráfico 03) para ponderar la magnitud de los cambios que el país ha experimentado durante los últimos once años.

El descenso del desempleo y, en términos más generales, el crecimiento de las oportunidades de acceder al empleo y la mejora de las condiciones de trabajo han tenido en los últimos años un correlato claro en las percepciones que se registran en los estudios de opinión pública. De todos modos, al igual que frente a otros indicadores que permiten ilustrar los tiempos de bonanza que el país ha disfrutado en la última década, al examinar la evolución del desempleo, se impone, al menos, una doble lectura o evaluación: por un lado, la economía uruguaya -por cierto, no solamente gracias a lo que algunos llaman "viento a favor" del contexto internacional- ha logrado generar fuentes de empleo y oportunidades; por otro, esta disminución del desempleo determina que seguir reduciéndolo implique abordar ciertos "núcleos duros" de la población (jóvenes con bajos niveles de capacitación, mujeres jefas de hogar, etc.) lo cual supone operar desde políticas laborales y sociales mucho más proactivas y radicales, sin descuidar la estabilidad razonable de las variables macroeconómicas que promueven el ambiente favorable para la expansión sostenida del empleo.

Así como el país registra en forma sostenida desde 2003 una mejora en los indicadores de empleo, salario e ingresos, desde 2005 se advierte una ininterrumpida reducción de los niveles de pobreza e indigencia. Entre 2004 y 2014 la incidencia de la pobreza y la indigencia en la población cayó, respectivamente, de $39, .9 \%$ a $9.7 \%$ y de $4.7 \%$ a $0.3 \%$ (Gráfico 04). De acuerdo al INE (2014, p. 26), la incidencia de la pobreza en 2014 en todo el país fue de $9.7 \%$, lo que constituye el registro más bajo de los últimos treinta años, tanto si se aplica la

\footnotetext{
${ }^{11}$ Con relación a este punto sostiene Gabriel Oddone: “¿Por qué la acumulación de capital y el aumento de la productividad han sido insuficientes para sostener el crecimiento en Uruguay? [...] [Porque] la inversión en Uruguay ha sido extraordinariamente baja. En efecto, la inversión anual promedio entre 1955 y 2000 alcanzó apenas al 13\% del PIB, un nivel comparativamente insuficiente para crecer de manera sostenida incluso si se tiene en cuenta el escaso aumento de la población del país." (2011, p.68).
} 
metodología de medición de la Línea de Pobreza del INE vigente (metodología 2006), como si se emplea la anterior metodología (Línea 2002). ${ }^{12}$ Por otro lado, si se utiliza la Línea de Pobreza de CEPAL, se puede afirmar que Uruguay alcanzó en 2012 el registro más bajo de la región y, además, el más bajo desde la década del sesenta: $3.9 \%$ en hogares y $6.1 \%$ en personas (Gráfico 04).

La reducción sostenida de la pobreza y la indigencia (que se inició, al igual que tras la crisis de 1982, con cierto retraso respecto al momento en que la economía retomó la senda expansiva) no debería ocultar que algunos de los rasgos más problemáticos siguen relativamente incambiados: por ejemplo su concentración territorial -asociada a procesos de segmentación residencial y exclusión social que comprometen la reproducción del "lazo social"- y su sobrerrepresentación en las generaciones más jóvenes. Uno de los retos que el país debe enfrentar sigue siendo el de asegurar la equidad entre generaciones en la prestación de servicios sociales, no solo por argumentos o razones de carácter normativo, sino por la necesidad de formar recursos humanos de calidad. Pese a la reducción de la pobreza, entre los hogares con niños y adolescentes -y por tanto en estos como grupo poblacional-, la "brecha" en el acceso al bienestar social con relación a los adultos y los adultos mayores sigue mereciendo atención. Si se emplean los valores de pobreza de CEPAL, la incidencia de la pobreza entre los uruguayos de 65 o más años de edad es prácticamente inexistente $(2.09 \%)$, mientras que entre los menores de 15 años (y por tanto entre sus familias) es de $21.3 \%$, lo que hace que la probabilidad de ser pobre entre los niños y adolescentes uruguayos -el segmento de la población en el que se supone se debería estar realizando la principal inversión en términos de desarrollo humano- sea más de diez veces superior que entre los adultos mayores. ${ }^{13}$ Mientras en la mayoría de los países de la región la reducción de la pobreza es una meta que implica trabajar prácticamente sobre todos los segmentos de la población y tipos de familia, en Uruguay (y en menor medida en los restantes países del Cono sur), habida cuenta del grado de desarrollo que su sistema de seguridad social ha alcanzado y, por ende, de los bajos niveles de pobreza que se observan entre sus adultos mayores, es un objetivo que implica reasignar prioridades y direccionar la inversión social hacia las familias con niños, adolescentes y jóvenes, familias que en una proporción elevada se componen por adultos perceptores de ingreso con bajo capital humano y social. ${ }^{14}$

Al descenso de la pobreza y la indigencia se suma desde 2007 la que parecería ser una tendencia lenta, pero persistente a la reducción de los niveles de concentración del ingreso. ${ }^{15}$ Como se puede apreciar en el siguiente Gráfico 05, se advierte a partir de 2007 una reversión de la tendencia al aumento de la desigualdad que el país comenzó a experimentar en el último lustro del siglo pasado. Si comparamos los valores de 2004 y 2014 (respectivamente, $0.46 \%$ y $0.38 \%$ ) se advierte esta tendencia a la reducción de la desigualdad en una magnitud por cierto para nada despreciable, habida cuenta de que se trata de un indicador que normalmente no registra variaciones bruscas en tanto mide un fenómeno (la concentración del ingreso monetario) de carácter estructural. ${ }^{16}$ Aunque estos registros son significativamente inferiores a

\footnotetext{
${ }^{12}$ Los valores más bajos que Uruguay registró en las últimas tres décadas, a excepción del 9,7\% para 2014, fueron los de mediados de los años noventa, que se situaban en torno a $15 \%$.

${ }^{13}$ Elaboración propia a partir de CEPAL: 〈http://websie.eclac.cl/infest/ajax/cepalstat.asp?carpeta=estadisticas〉.

${ }^{14}$ Para mayor detalle, ver: Gustavo De Armas, Estado de Bienestar, infancia y políticas públicas en Uruguay. Hacia un nuevo y necesario contrato intergeneracional por el desarrollo, Montevideo, Ed. CLAEH, 2009.

15 Sobre el tema de la distribución del ingreso en Uruguay deben consultarse los trabajos más recientes de Verónica Amarante y Andrea Vigorito.

${ }^{16}$ De todos modos, cabe referir nuevamente el rezago histórico de estos indicadores en Uruguay. Según las estimaciones realizadas por Álvarez y Bértola (2010, p; 62), el Coeficiente de Gini en Uruguay alcanzó hacia
} 
los que el país alcanzó tras la crisis de 2002, siguen siendo notoriamente mayores a los que en promedio exhiben los países más desarrollados. ${ }^{17}$ También a los que el país supo exhibir en las décadas de mayor arraigo de su Estado de Bienestar. De todos modos, los valores alcanzados por el país en los últimos dos años (0.38) resultan relativamente comparables, por ejemplo, con los registrados al cabo de 2011 en países como España, Grecia y Portugal (en los tres casos, $0.34 \%)^{18}$

Sin desconocer ni subestimar la significación de esta reciente, pero sostenida tendencia a la disminución de la desigualdad en la distribución de la renta, en un contexto de crecimiento real de los ingresos de los hogares y de reducción de la pobreza monetaria, a nadie escapa que la fragmentación social que se fue instalando en la sociedad uruguaya durante las últimas décadas todavía no termina de ceder terreno de manera clara. A su vez, las variables e indicadores que nos permiten medir los distintos aspectos de la distribución de oportunidades en la sociedad (por ejemplo, los niveles de escolarización formal alcanzados entre los jóvenes) exhiben valores inquietantes y, en algunos casos, relativamente inmóviles en los últimos decenios, pese al crecimiento económico observado, la disminución de la pobreza y la desigualdad consignadas, así como el incremento del gasto público social.

La reversión de la tendencia al aumento de la desigualdad que desde mediados de los años noventa del siglo pasado hasta 2007 experimentó Uruguay, constituye en sí misma, con independencia de la magnitud del cambio, una bienvenida novedad. Por cierto, la atribución causal de esta reversión no resulta una tarea sencilla y menos exenta de polémica política y aun técnica.

Más allá de la contribución que algunas políticas o reformas sociales pudieron haber realizado sobre este particular, junto a otras estrictamente económicas, en esta mejora en la distribución del ingreso (por ejemplo, los programas de transferencias monetarias, en particular el nuevo Régimen de Asignaciones Familiares introducido en 2008), la evidencia parece indicar que el incremento en la desigualdad que el país experimentó previamente obedeció al aumento en la disparidad de ingresos entre los trabajadores más calificados y los menos calificados, lo que implica ubicar la equidad de la educación al tope de la agenda de debate sobre la igualdad.

La apelación a las políticas sociales (en su doble faz de protección frente a las diversas fuentes de riesgo y de desarrollo y de promoción de las capacidades de los ciudadanos) como uno de los instrumentos principales para reducir la desigualdad resulta en el presente bastante más que una mera expresión de deseo. Si bien históricamente Uruguay ha sido uno de los países de la región que más recursos ha destinado a las políticas sociales, el aumento en términos absolutos del gasto per cápita, determinado fundamentalmente por el crecimiento

finales de los años cincuenta del siglo pasado un valor levemente inferior a 0.3 , comparable, por lo tanto, con los registros de desigualdad en la distribución del ingreso que han caracterizado en la segunda mitad del siglo veinte a los países más desarrollados, en particular, a aquellos que lograron construir regímenes de bienestar más robustos (DE ARMAS \& RAMOS, 2011).

17 Entre los 25 países europeos sobre los que se presentan datos de Gini para 2011 en las bases on line de Eurostat 〈http://epp.eurostat.ec.europa.eu/portal/page/portal/statistics/themes〉 el promedio simple es de 0.287.

${ }^{18}$ De hecho, la distancia que separa al Gini de Uruguay del promedio simple entre los valores de estos tres países del Mediterráneo (respectivamente, 0.38 y 0.339) es similar a la que media entre estos y el promedio simple de Europa (respectivamente, 0.339 y 0.287). En esa misma línea se puede agregar que los países del Mediterráneo mencionados exhiben niveles de desigualdad más próximos a los de Uruguay que a los de sus vecinos del norte de Europa: $\quad$ Noruega (0.229), Suecia $\quad(0.244) \quad$ o $\quad$ Finlandia $\quad(0.258)$ 〈http://epp.eurostat.ec.europa.eu/portal/page/portal/statistics/themes〉. 
económico y por una leve expansión de su prioridad macroeconómica, ubican en la actualidad al país entre los que más recursos asignan al campo de las políticas sociales.

Como final de este recorrido, y sin pretender establecer una relación mecánica entre tendencias económicas y sociales positivas, con su correlato en las percepciones de los ciudadanos y en las tendencias migratorias, no se debería subestimar el hecho de que por primera vez en varias décadas parecería revertirse, o al menos atemperarse, la constante sangría poblacional de ciudadanos uruguayos que emigran en busca de un mejor destino personal y familiar. Por cierto, dicha reversión no ha sido continua y se da en un contexto internacional caracterizado por las recesiones que padecen los países más desarrollados, algunos de los cuales (España y Estados Unidos) han sido, durante las últimas décadas, uno de los destinos preferidos de los emigrantes uruguayos.

En suma, esta década de un Uruguay gobernado por la izquierda puede ofrecer un balance auspicioso, más allá de las naturales controversias que un ensayo de este tipo siempre podrá entrañar. En ese sentido, el planteo de los partidos de la oposición respecto a la noción de "década perdida" no parece tener fundamento científico serio. La sociedad uruguaya se encuentra a comienzos de 2016 en una posición claramente más favorable que a comienzos del pasado decenio para enfrentar los retos que aún debe necesariamente sortear si es que pretende alcanzar en el mediano plazo un nivel de desarrollo cualitativamente superior.

\section{DEMOCRACIA Y DESARROLLO: LA HORA DEL "IMPULSO”}

A comienzos del 2016, mientras se escribe este texto, el tercer gobierno consecutivo del Frente Amplio está en los umbrales de cumplir el primero de su período de cinco años. Los avatares con que viene transcurriendo esta segunda presidencia de Tabaré Vázquez parecen corroborar ciertos desafíos e incertidumbres que ya se perfilaron durante el último ciclo electoral 2014-2015 (CAETANO \& SELIOS, 2015). El deterioro del contexto económico regional e internacional ha sido más severo y acelerado que lo previsto, confirmando un cuadro consistente de desaceleración económica. El crecimiento de la conflictividad social durante 2015 revela a una sociedad que, pese a las mejoras, se ha vuelto más demandante y que no otorga cheques en blanco a nadie. El principal reto para la izquierda gobernante apunta a demostrar que puede gobernar también en ciclos económicos en más de un sentido adversos y que puede hacerlo sin paralizar su plan de transformaciones, por el que se comprometió ante la ciudadanía que la eligió. En cualquier hipótesis, treinta años después del final de la dictadura, la democracia uruguaya se revela sólida y arraigada. Ello por cierto no resulta poca cosa, dentro de una América Latina en la que los desacuerdos de régimen parecen profundizarse peligrosamente.

En ese contexto, resulta imperativo plantear algunos de los principales desafíos que enfrenta la izquierda uruguaya desde una hipótesis interpelante: luego de más de una década de crecimiento económico ininterrumpido, con tendencias virtuosas en buena parte de los indicadores sociales más relevantes, con una revolución productiva en curso y con un contexto internacional que tiende a desacelerarse, pero en el que no se atisban amenazas concretas de crisis o recesión para el país, la hipótesis del desarrollo configura un desafío razonablemente realista, que exige reformas estructurales complejas e impostergables, pero que ofrece un cuadro de oportunidades tal vez inédito desde la segunda postguerra hasta nuestros días. 
¿Es esta una hipótesis pertinente? ¿Puede Uruguay convertirse en un país desarrollado en los próximos años? Estas preguntas pueden generar más de una perplejidad inmediata a muchos lectores. De hecho, se trata de una interpelación que desde hace por lo menos setenta años ha estado ausente de la agenda política nacional y del imaginario político de los uruguayos. Sin embargo, en los últimos años algunas voces -tanto provenientes del elenco político como de la academia- han comenzado a reincorporar este interrogante al debate público, ya sea para afirmar su pertinencia o para desestimarla. Cabe señalar que esto es registrado también por los observadores fuera de fronteras, como veremos más adelante. Para un país que, como el Uruguay, ha encontrado sus mejores versiones desde las reformas de anticipación, el ejercicio intelectual y político de tomarse en serio la pregunta sobre las posibilidades del desarrollo cercano parece por lo menos fecundo y, en cierto sentido, insoslayable.

¿El "salto" al desarrollo resulta un futuro posible mínimamente razonable y persuasivo o es tan solo un eslogan o una mera consigna? ¿Esta pregunta solo esconde la restauración de la autocomplacencia de una vivencia provinciana y desaprensiva de la prosperidad (una suerte de retorno diferente de aquella "bovina euforia" que denunciara hace décadas Carlos Quijano), ${ }^{19} \mathrm{o}$ en ella converge el rumbo más radical de las interpelaciones que los uruguayos deben asumir para estar a la altura de las circunstancias? ¿Se barrunta allí un ejercicio reflexivo que pueda contribuir a un mayor rigor conceptual a la hora de encarar los desafíos más profundos del Uruguay actual gobernado desde hace más de una década por la izquierda?

Hoy en el mundo y en la región se ha vuelto a discutir sobre el tema del desarrollo. Aunque los marcos del debate ideológico han cambiado y el concepto de "modelo" genera legítimos reparos, los enfoques y estrategias para el desarrollo vuelven al ruedo de la discusión política. No es una casualidad que ello se produzca en forma coincidente a la erosión manifiesta de las máximas pretenciosas del pensamiento neoconservador propuesto como "pensamiento único". Aunque algunos de sus postulados conceptuales prolonguen insólitamente su vigencia en elencos políticos poco audaces y actualizados, en el timón de los gobiernos y de las políticas públicas es donde se vuelve más evidente la necesidad de superar ese cortoplacismo ramplón que niega el debate por el futuro deseable, por el desarrollo. Y tampoco es una mera casualidad que, al tiempo que se vuelve a discutir sobre el desarrollo, se vuelve a debatir con fuerza sobre los derechos y su nueva agenda. En realidad, esas dos operaciones forman parte de un mismo movimiento: la renovada impugnación de atender las nuevas exigencias de la igualdad política, social o cultural tiene tanto que ver con la discusión sobre el desarrollo como el debate acerca de las estrategias de inserción internacional o sobre las políticas económicas más aptas para los contextos contemporáneos. Como bien señala la CEPAL en sus últimos trabajos, esto resulta particularmente central en América Latina, el continente más desigual del planeta, aquel en el que resulta más indiscutible que avanzar en la igualdad social es también una condición indispensable para sustentar el crecimiento económico. Pero la "hora de la igualdad" a la que convoca la CEPAL choca contra la ausencia de pensamiento estratégico en el continente. Y el Uruguay no es una excepción a este respecto.

De una manera o de otra, en la última campaña electoral, partidos y candidatos también los del Frente Amplio- no parecen haber advertido en su radicalidad la entidad que toma el tema de un desarrollo posible del Uruguay en la actual coyuntura histórica. Desde la

${ }^{19}$ Carlos Quijano (1900-1984) fue el fundador en 1939 del legendario semanario de izquierda independiente "Marcha". 
oposición, con seguridad por razones de competencia política, como vimos se llega a hablar de la "década perdida". Como se ha advertido, si se repasan los indicadores sociales y económicos de este último decenio, como vimos, no resulta sencillo fundamentar ese diagnóstico. Cualquier observador independiente que repase la evolución del PBI, los niveles de crecimiento de la productividad en ciertos sectores estratégicos, la evolución de las tasas de inversión, de la pobreza, de la indigencia, de la distribución del ingreso, de la desocupación, del salario real, de los derechos concretos de los trabajadores, no puede argumentar en forma sólida en esa dirección.

En otro orden, el hecho que ningún candidato de la oposición haya argumentado en las últimas dos campañas en favor de retornar a la desregulación de las relaciones laborales propias del período 1991-2005 constituye un reconocimiento implícito de que hay avances irreversibles que llegaron para quedarse, gobierne quien gobierne.

Pero tampoco desde tiendas oficialistas - creemos - se ha asumido con la radicalidad debida las exigencias del desafío de un desarrollo posible. El optimismo que nutre una novedosa percepción colectiva de bienestar a menudo suele nutrir la desmemoria de los tiempos difíciles y vuelve a la ciudadanía mucho más exigente. Ello forma parte también del éxito: las demandas crecen, los ciudadanos exigen nuevos derechos, los discursos que otrora persuadieron hoy no funcionan de modo tan efectivo. Desde tiendas frenteamplistas, los fundamentos que en la primera parte del último ciclo electoral pudieron sustentar la filosofía del "vamos bien", ${ }^{20}$ en la parte final de la campaña, pero sobre todo durante este primer año del nuevo gobierno frenteamplista de Vázquez, no han podido ocultar la visibilidad de ciertos desajustes y sus desafíos consiguientes. El contraste marcado entre el crecimiento de la economía y la situación de deterioro que exhiben aspectos claves para una sociedad desarrollada (como son el nivel de cohesión social en temas como seguridad o salud, los desempeños del sistema educativo o las bases de infraestructura para hacer sustentable la continuidad del despegue productivo, entre otros), interpelan de modo radical toda autocomplacencia en las evaluaciones. Más allá de algunos avances sectoriales, la situación de la enseñanza uruguaya sigue planteando déficits inadmisibles que al tiempo que significan un bloqueo al desarrollo, ponen en duda la solidez de los avances sociales obtenidos. Si no se avanza en la enseñanza, la vulnerabilidad social puede minar desde el núcleo las políticas de inclusión. Lo mismo puede decirse en relación al "apagón logístico" que desafía desde sus raíces la revolución productiva en curso. Los "buques insignia" tantas veces anunciados durante el anterior gobierno de José Mujica (el puerto de aguas profundas, las nuevas carreteras, la recuperación efectiva del tren, la regasificadora, etc.) no han podido echarse de una vez al mar. El desarrollo de la investigación en ciencia y tecnología, otro de los escenarios en los que se ha producido en las décadas más recientes una "revolución silenciosa", requiere una inversión pública reforzada y "blindada" en términos políticos, como otra clave estratégica para el futuro.

A partir de las cuentas pendientes de la administración anterior y en particular de las dificultades acrecentadas que han enmarcado el primer año del tercer gobierno frenteamplista, la interpelación exigente de un desarrollo posible debería arraigar la convicción de que "más

\footnotetext{
20 "Vamos bien" fue el eslogan de campaña que utilizó como candidato Tabaré Vázquez durante la primera etapa de la campaña electoral de 2014. Ante las críticas recibidas y el escaso éxito del mismo, fue luego cambiado por el de "Uruguay no se detiene".
} 
de lo mismo no alcanza". El impacto de iniciativas como las del "Plan Ceibal" 21 en su momento o los logros de la transformación extraordinaria de la política energética en el último quinquenio, ${ }^{22}$ son buenos ejemplos del tipo de acciones que se exigen para dar respuesta efectiva a esta hipótesis de un desarrollo posible. Se lo mire desde donde se lo mire, el pleito acerca de si se están aprovechando las oportunidades de la bonanza económica todavía está en curso. Con sensatez y mirada estratégica, no sería sensato dejar pasar este momento del país para agitar los verdaderos debates acerca del futuro cercano de los uruguayos, en especial desde la exigencia acuciante de quienes más necesitan del desarrollo que, no lo olvidemos, son siempre los más necesitados.

Y por supuesto que cuando se habla de desarrollo, se debe hablar de democracia y de derechos, de la calidad de ambos. En casi todos los rankings y mediciones internacionales que hacen referencia a la situación de los países de la región respecto a valores clásicos de la democracia, el Uruguay marca muy bien y en los últimos años ha incluso acrecido su prestigio. Más allá de todas las múltiples referencias que han hecho de Uruguay un "país de moda" a nivel internacional, muy unidas a la concreción de leyes vinculadas a la llamada agenda de nuevos derechos, ${ }^{23}$ como al fenómeno ya referido del boom de popularidad global del Presidente José Mujica, el país ha confirmado sus altas calificaciones en varios observatorios internacionales, que refieren precisamente a la valoración internacional de variables que hacen a la calidad de las democracias.

Sin embargo, más allá de la significación de estos registros, en varios planos la ciudadanía uruguaya no se ha mantenido ajena al panorama de insatisfacción que mayoritariamente reina en torno a la calidad de la democracia en la mayoría de los países del continente. Por lo menos, más allá de la contundencia de los resultados electorales finales a favor de la izquierda en octubre y noviembre de $2014,{ }^{24}$ los avatares de la campaña pasada reflejaron también -más allá de la "realidad virtual" generada por el fracaso de las encuestadoras- un escenario de contrastes, que objetivamente podría derivar en contextos adversos en un factor de bloqueo para muchas de las reformas estructurales que el país debe encarar para acceder a mejores niveles de desarrollo. Una de las principales referencias en este sentido se fundan, por ejemplo, en la particularidad de combinar una de las mayores brechas de distanciamiento entre altos grados de adhesión a valores y prácticas democráticas, que sigue demostrando la población, y un cuadro más variopinto en algunos niveles claves de la participación política y en relación a la existencia de fuertes desconfianzas interpersonales en la vida cotidiana.

\footnotetext{
${ }^{21}$ El Plan Ceibal es un proyecto socioeducativo, creado por el gobierno uruguayo presidido por Tabaré Vázquez por decreto del 18 de abril de 2007, con el objetivo de "proporcionar un computador portátil a cada alumno en edad escolar y a cada maestro de la escuela pública, así como también capacitar a los docentes en el uso de dicha herramienta, para promover la elaboración de propuestas educativas acordes con las mismas". La sigla Ceibal es un retroacrónimo que significa "Conectividad Educativa de Informática Básica para el Aprendizaje en Línea".

${ }^{22}$ En el último quinquenio, a instancias de las políticas públicas aplicadas por la Dirección Nacional de Energía, el Uruguay se ha acercado a tener cerca de la mitad de su matriz energética en formas de energía renovable.

${ }^{23}$ Entre ellas pueden destacarse las leyes de despenalización del aborto, de matrimonio igualitario, de regulación del consumo de mariguana, entre otras.

${ }^{24}$ El Frente Amplio obtuvo en la primera vuelta de octubre de 2014 un 47,8\% de los votos emitidos, distanciándose de su principal contendor que fue el P. Nacional que logró 30, 9\%. En la segunda vuelta realizada en noviembre, la fórmula presidencial frenteamplista de Vázquez-Sendic obtuvo 53,5\% contra 41,2\% de la fórmula nacionalista Lacalle Pou-Larrañaga, en lo que fue la mayor ventaja efectivizada en un ballotaje desde la aplicación de las reglas emanadas de la reforma constitucional de 1996.
} 
Para citar uno de los ejemplos más escandalosos, si nos concentramos en los registros que aluden al peso específico de las mujeres en la política uruguaya, con seguridad nos encontraremos con una de las contradicciones más flagrantes -sino la máxima- que afecta la calidad de la democracia uruguaya. En la publicación El Mapa 2014 de las Mujeres en Política, lanzado en marzo del 2014 por la "Unión Interparlamentaria" (UIP) y "ONU Mujeres", Uruguay se ubicaba en el ranking de clasificación por debajo del promedio mundial y como uno de los peor ubicados en la región. Como se señala en el Comunicado de Prensa de ambas organizaciones al presentar el referido Mapa: "En cuanto al porcentaje de mujeres en puestos ministeriales, Uruguay se ubica $\mathrm{N}^{\circ} 60$ en el ranking, incluso por debajo de países como Emiratos Árabes (n.55). El promedio de 14.3\% se encuentra por debajo del promedio mundial de 17,2\% y del promedio de América de $22.9 \%$. En cuanto a la región de América del Sur, Uruguay ocupa el peor lugar. Con respecto al porcentaje de mujeres en el parlamento, Uruguay se ubica n. 103 con un promedio de $13,1 \%$, por debajo de la media mundial $(21,8 \%)$ e incluso de la media de los países del mundo árabe (16\%). En América del Sur, Uruguay solo está mejor que Colombia y Brasil". ${ }^{25}$

De todos modos, a sabiendas de que hay elementos no medibles directamente sino evaluables desde perspectivas analíticas cualitativas, parecería que es posible decir que sigue predominando entre los uruguayos una visión autocomplaciente sobre el estado general de su democracia, fortalecido además en la comparación inmediata con las situaciones vividas por los restantes países de la región y del continente. El predominio de este relato autocomplaciente, que tiene viejas razones y raíces, no hace más que opacar la visión de algunos problemas reales y efectivos en varias dimensiones. Cierta atonía y hasta desaliento exhibidos por franjas importantes de la ciudadanía respecto al nivel de las propuestas y debates del ciclo electoral pasado, ¿no están también reflejando esos problemas e inconsistencias más profundas de la democracia uruguaya que a menudo invisibilizamos? Más allá de los análisis de la coyuntura y de los resultados finales del proceso electoral, ¿estamos entendiendo realmente lo que ha pasado y lo que realmente está pasando en la política uruguaya?

Un distanciamiento de la soberbia debería alentar a la izquierda uruguaya a no apresurar respuestas y mucho menos alentar triunfalismos aldeanos. Una hipótesis pertinente podría emerger de una mirada más rigurosa y menos autocomplaciente, desde una perspectiva más larga y centrada en las exigencias concretas del reclamo de los ciudadanos descontentos y "no creyentes", todavía una minoría pero que crece y que en cualquier hipótesis cada vez será más decisiva. Con seguridad, de allí podrían salir pistas sobre asuntos que por debajo de la superficie registran contrastes fuertes en la vida democrática de Uruguay, la mayoría de los cuales, de persistir, constituirá un bloqueo cierto para la consolidación de perfiles de progresismo genuino. Esas contradicciones que se advierten parecen confrontar una situación razonablemente buena en términos de la "sintaxis" de la política - reglas de juego, seguridad jurídica, garantías, estabilidad política, previsibilidad - con una muy asimétrica en relación a ciertos elementos de la "semántica" - ejercicio efectivo de los derechos adquiridos, igualdad práctica, efectividad de ciertas políticas públicas en áreas sensibles, capacidades anticipatorias, propuestas estratégicas- de una democracia de calidad y a la altura de las exigencias de estos tiempos de cambio vertiginoso.

\footnotetext{
${ }^{25}$ Cfr. ONU Mujeres. COMUNICADO DE PRENSA. Presentación Mapa 2014 de las Mujeres en Política.
} 
En cualquier hipótesis, pese a los logros obtenidos y a la desaceleración de la coyuntura más actual, podría decirse que no es la hora del "freno" sino la del "impulso", parafraseando una expresión emblemática del reconocido intelectual uruguayo Carlos Real de Azúa. ${ }^{26}$ Una izquierda transformadora que se detiene "a mitad del camino" deviene a menudo en políticas de conservación encubiertas. Resulta necesario reiterarlo: tal vez no estemos entendiendo suficientemente lo que está pasando en el terreno más concreto de los comportamientos de los ciudadanos uruguayos "realmente existentes". La democracia uruguaya también está mutando, aunque en los ritmos y formatos que prefieren sus ciudadanos. Anticipar este desafío y darle respuestas consistentes para nadie resulta más imperativo que para la izquierda.

\section{BIBLIOGRAFÍA}

ALTIMIR, Oscar. Distribución del ingreso e incidencia de la pobreza a lo largo del ajuste. Revista de la CEPAL, n. 96, pp. 96-119, 2008.

ALTIMIR, Oscar. La dimensión de la pobreza en América Latina. Santiago de Chile: CEPAL, 1979.

ÁLVAREZ, Jorge; BÉRTOLA, Luís. Desarrollo y desigualdad: miradas desde la historia económica. In: SERNA, Miguel (Org.). Pobreza y (des)igualdad en Uruguay: una relación en debate. Buenos Aires: CLACSO, 2010.

BÉRTOLA, Luís; BITTENCOURT, Gustavo. Veinte años de democracia sin desarrollo económico. In: CAETANO, Gerardo. 20 años de democracia. Uruguay 1985-2005: miradas múltiples. Montevideo: Taurus, 2005.

BUQUET, Daniel; DE ARMAS, Gustavo. La evolución electoral de la izquierda: crecimiento demográfico y moderación ideológica. In: LANZARO, Jorge (Coord.). La izquierda uruguaya entre la oposición y el gobierno. Montevideo: Fin de siglo, 2004.

CAETANO, Gerardo; SELIOS, Lucía. Análise do ciclo eleitoral uruguaio e dos erros das enquestadoras. Tempo Exterior: Revista de Análise e Estudos Internacionais, v. 15, n. 30, pp. 79-107, 2015.

COMISIÓN ECONÓMICA PARA AMÉRICA LATINA (CEPAL). Panorama social de América Latina y el Caribe 201. Santiago de Chile, 2012.

\footnotetext{
${ }^{26}$ La expresión alude al clásico libro de Carlos Real de Azúa, "El impulso y su freno. Tres décadas de batllismo", editado por Ediciones de la Banda Oriental en 1964.
} 
COMISIÓN ECONÓMICA PARA AMÉRICA LATINA (CEPAL). Panorama social de América Latina y el Caribe 2011. Santiago de Chile, 2011.

COMISIÓN ECONÓMICA PARA AMÉRICA LATINA (CEPAL). Panorama social de América Latina y el Caribe 2010. Santiago de Chile, 2010.

COMISIÓN ECONÓMICA PARA AMÉRICA LATINA (CEPAL). Panorama social de América Latina y el Caribe 2009. Santiago de Chile, 2009.

COMISIÓN ECONÓMICA PARA AMÉRICA LATINA (CEPAL). Panorama social de América Latina y el Caribe 2007. Santiago de Chile, 2007.

COMISIÓN ECONÓMICA PARA AMÉRICA LATINA (CEPAL). Panorama social de América Latina y el Caribe 2004. Santiago de Chile, 2004.

DE ARMAS, Gustavo; RAMOS, Conrado. La evolución de los Sistemas de Bienestar en América Latina. Santiago de Chile: Cieplan, 2011.

DE ARMAS, Gustavo. Debilitamiento del efecto demográfico y consolidación de un nuevo sistema de partidos: evidencia de las elecciones de 2009 en Uruguay. Revista Uruguaya de Ciencia Política, n.18, Montevideo, 2009.

DE ARMAS, Gustavo. Estado de bienestar, infancia y políticas públicas en Uruguay. Hacia un nuevo y necesario contrato intergeneracional por el desarrollo. Montevideo: CLAEH, 2009.

GARCÉ, Adolfo; YAFFÉ, Jaime. La era progresista. El gobierno de izquierda en Uruguay: de las ideas a las políticas. Montevideo: Fin de Siglo, 2005.

INSTITUTO NACIONAL DE ESTADÍSTICA (INE). Estimación de la pobreza por el método de ingreso. Año 2013. Montevideo, 2014.

INTERNATIONAL MONETARY FUND (IMF), World Economic Outlook Database, octubre, 2015.

Disponible en: <http://www.imf.org/external/pubs/ft/weo/2015/02/weodata/weoselgr.aspx>. 
LANZARO, Jorge. La izquierda se acerca a los uruguayos y los uruguayos se acercan a la izquierda. Claves de desarrollo del Frente Amplio. In: LANZARO, Jorge (Coord.). La izquierda uruguaya entre la oposición y el gobierno. Montevideo: Fin de siglo, 2004.

LUPPI, Carlos. La historia no oficial de la crisis y una lección pendiente. Montevideo: Sudamericana, 2012.

MELGAR, Alicia. Distribución del ingreso en el Uruguay. Serie Investigaciones, n. 18. Montevideo: CLAEH, 1981.

ODDONE, Gabriel. Restricciones para sostener el crecimiento: lecciones y desafíos para las políticas públicas. In: AROCENA, Rodrigo; CAETANO, Gerardo (Coord.). La aventura uruguaya: el país y el mundo. Montevideo. Sudamericana, 2011.

PAOLILlO, Claudio. Con los días contados. Montevideo: Búsqueda-Fin de Siglo, 2004.

STÉNERI, Carlos. Al borde del abismo. Uruguay y la gran crisis del 2002-2003. Montevideo: EBO, 2011.

YAFFÉ, Jaime. Al centro y adentro: la renovación de la izquierda y el triunfo del Frente Amplio en Uruguay. Montevideo: Linardi y Risso, 2005.

\section{APÉNDICES}




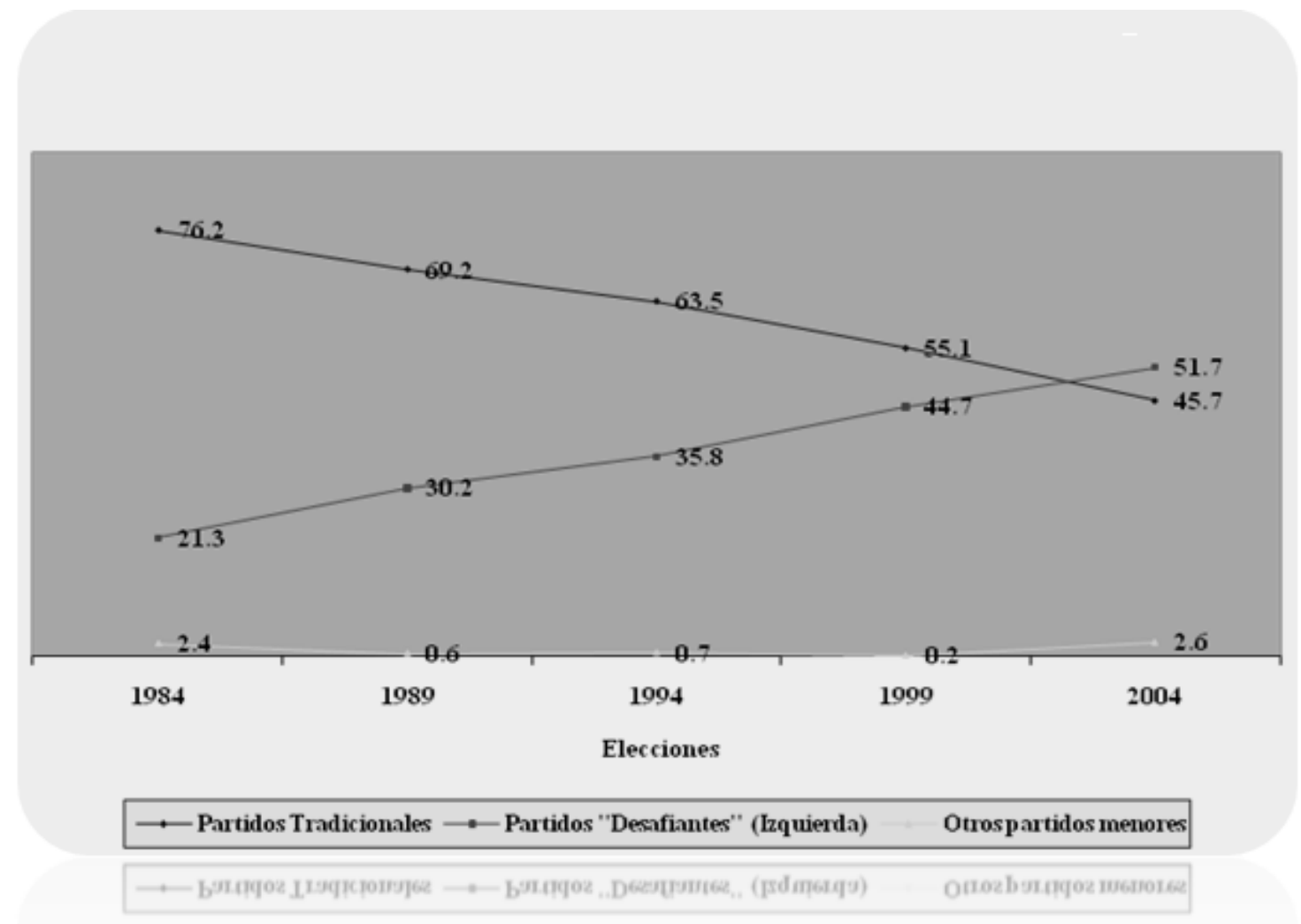

\section{GRÁFICO 01 - EVOLUCIÓN DEL SISTEMA DE PARTIDOS URUGUAYOS POR BLOQUES PARTIDARIOS (1984-2004).}

Fuente: elaboración propia a partir de la Area de Politica y RR II del banco de dados de la FCS/UDELAR

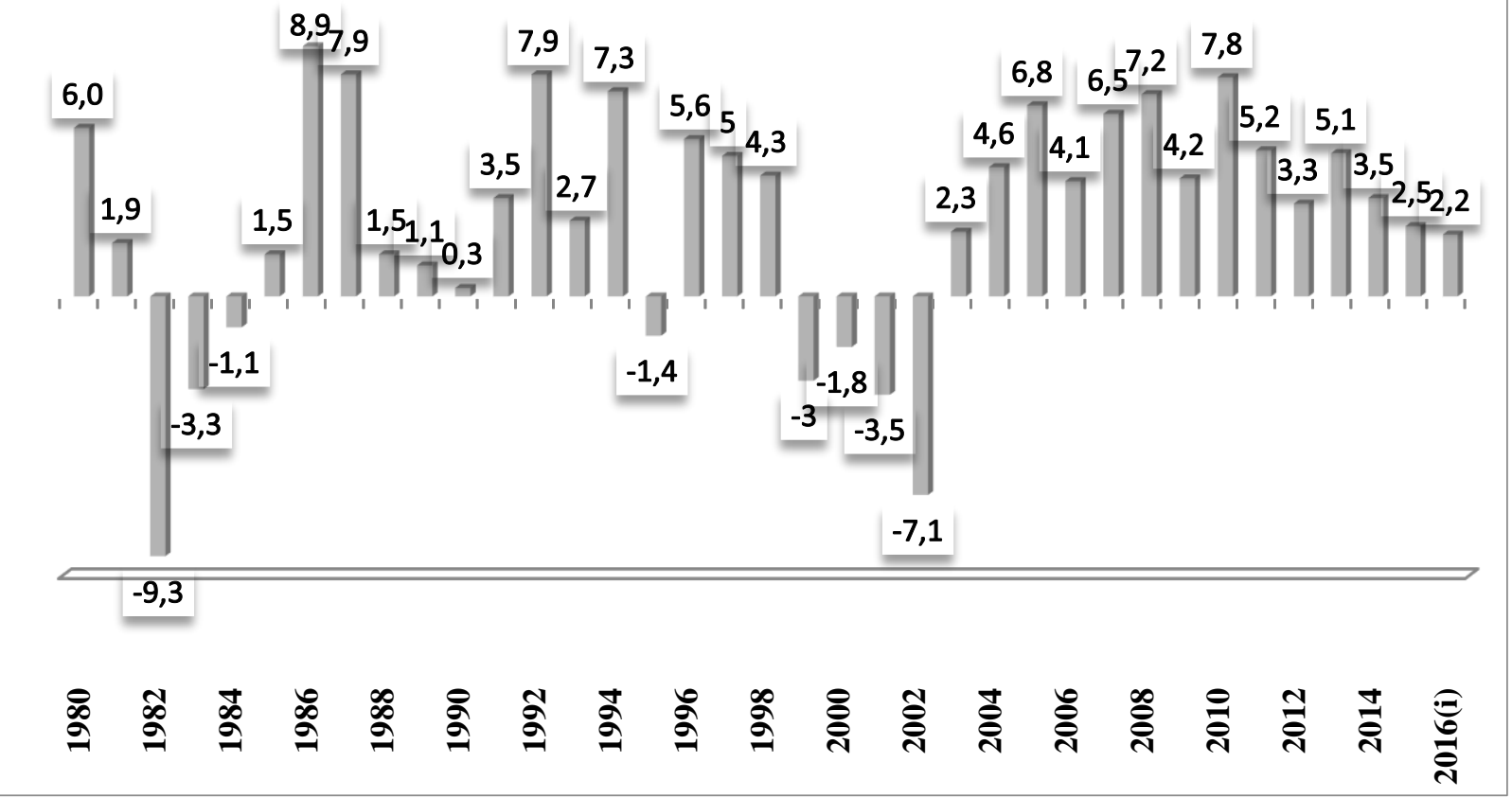


GRÁFICO 02 -VARIACIÓN DEL PIB (MEDIDO EN \$U A PRECIOS CONSTANTES) EN URUGUAY (1980-2016).

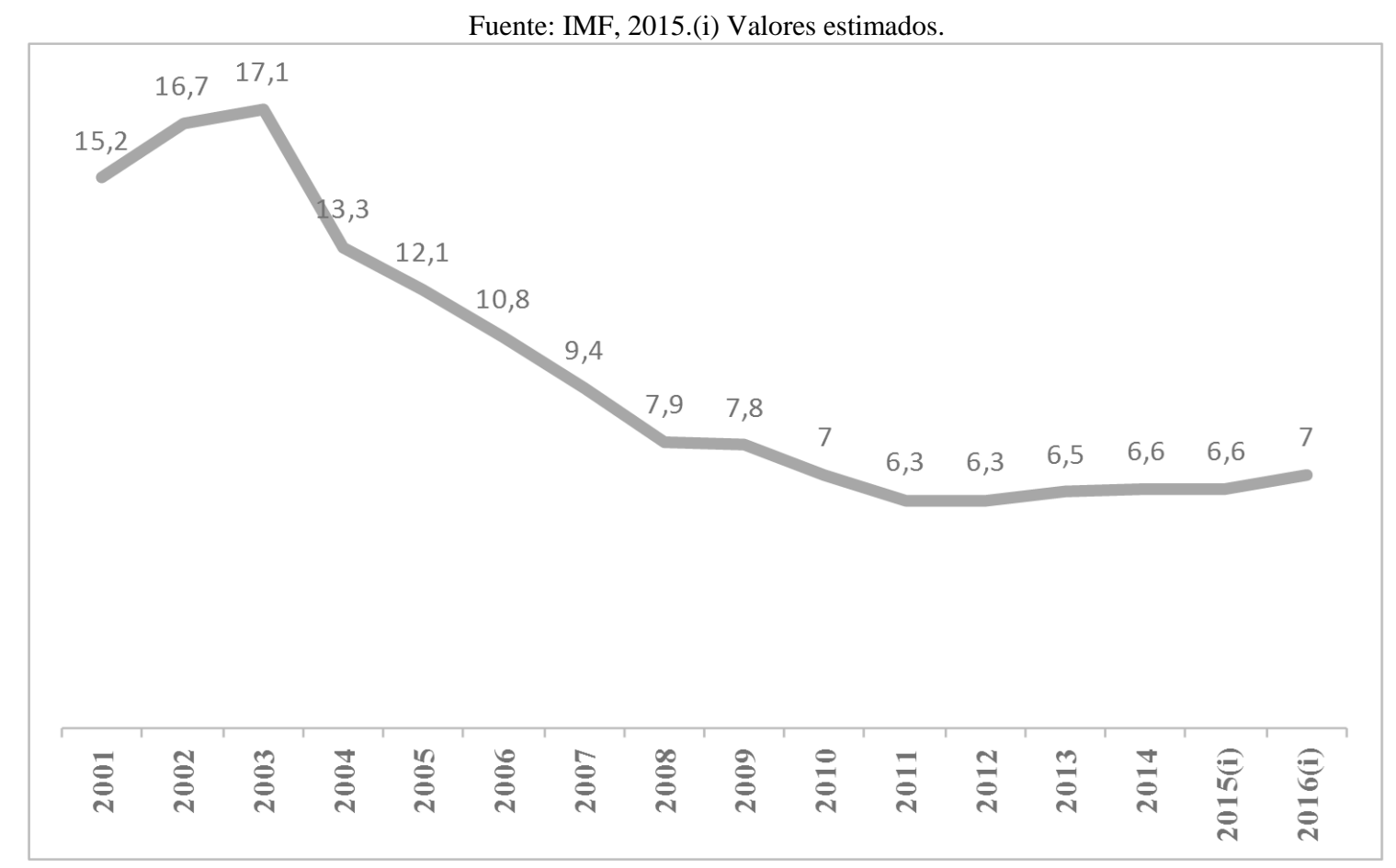

GRÁFICO 03 - TASA DE DESEMPLEO EN URUGUAY (LOCALIDADES DE $5000 \mathrm{Y}$ MÁS HABITANTES -2001-2016).

Fuente: Fuente: IMF, 2015.(i) Valores estimados. 


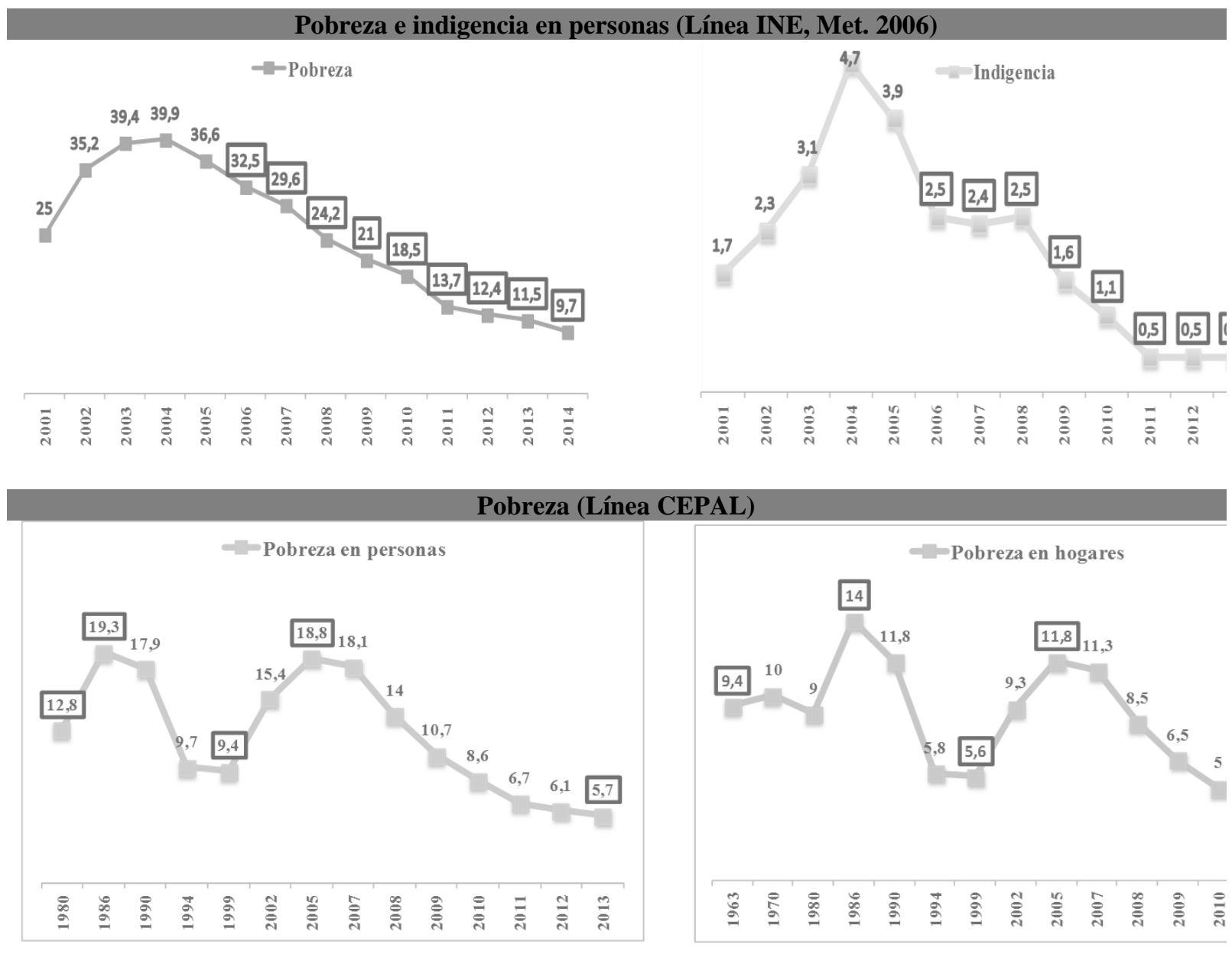

\section{GRÁFICO 04 - INCIDENCIA DE LA POBREZA Y LA INDIGENCIA EN HOGARES Y PERSONAS EN URUGUAY (ÁREAS URBANAS, SALVO EN LOS AÑOS QUE SE DESTACAN[I] DONDE LA INFORMACIÓN CORRESPONDE A TODO EL PAÍS) DE ACUERDO A LÍNEA INE (MET. 2006) Y CEPAL. SERIES 2001-2013 Y 1963-2012. EN PORCENTAJES.}

Fuentes: los dos primeros gráficos, elaboración propia a partir del INE (2014 p.22 y 29) e INE (2012: 18 y 23), salvo para los registros de 2001 que corresponden a INE (2008, p. 77) y los de 2014 que corresponden a INE (2015, p.22 y 27). Para el segundo gráfico, elaboración propia a partir de las siguientes fuentes: el dato de 1963 corresponde a Melgar (1981); el de 1970 a Altimir (1979, p.63); los de 1980 y 1986 a Altimir (2008, p.100); los de 1990 y 1994 a CEPAL (2004, p. 328-329); los de 1999, 2002, 2008 y 2009 a CEPAL (2010, p. 78-79); el de 2005 a CEPAL (2007, p. 56-57); el de 2007 a CEPAL (2009, p. 54-55); el de 2010 a CEPAL (2011, p. 52); el de 2011 a CEPAL (2012, cap. I, p.43) 〈http://www.eclac.org/publicaciones/xml/5/48455/PanoramaSocial2012DocICap1.pdf $>$ y el de 2012 a CEPAL (2013, cap. I, p.54) $\mathrm{http} / /$ www.cepal.org/publicaciones/xml/9/51769/CapituloI-versionpreliminar.pdf . Para el tercer gráfico, elaboración propia a partir de datos de la base on line de CEPAL 〈http://websie.eclac.cl/infest/ajax/cepalstat.asp?carpeta=estadisticas〉, excepto para el año 2011, cuyo registro fue extraído de CEPAL (2012, ibíd.), y para el año 2012, cuyo registro fue extraído de CEPAL (2013, ibíd.).

Nota: [i] los datos que aparecen en el primer gráfico a partir de 2006 corresponden a todo el país. 


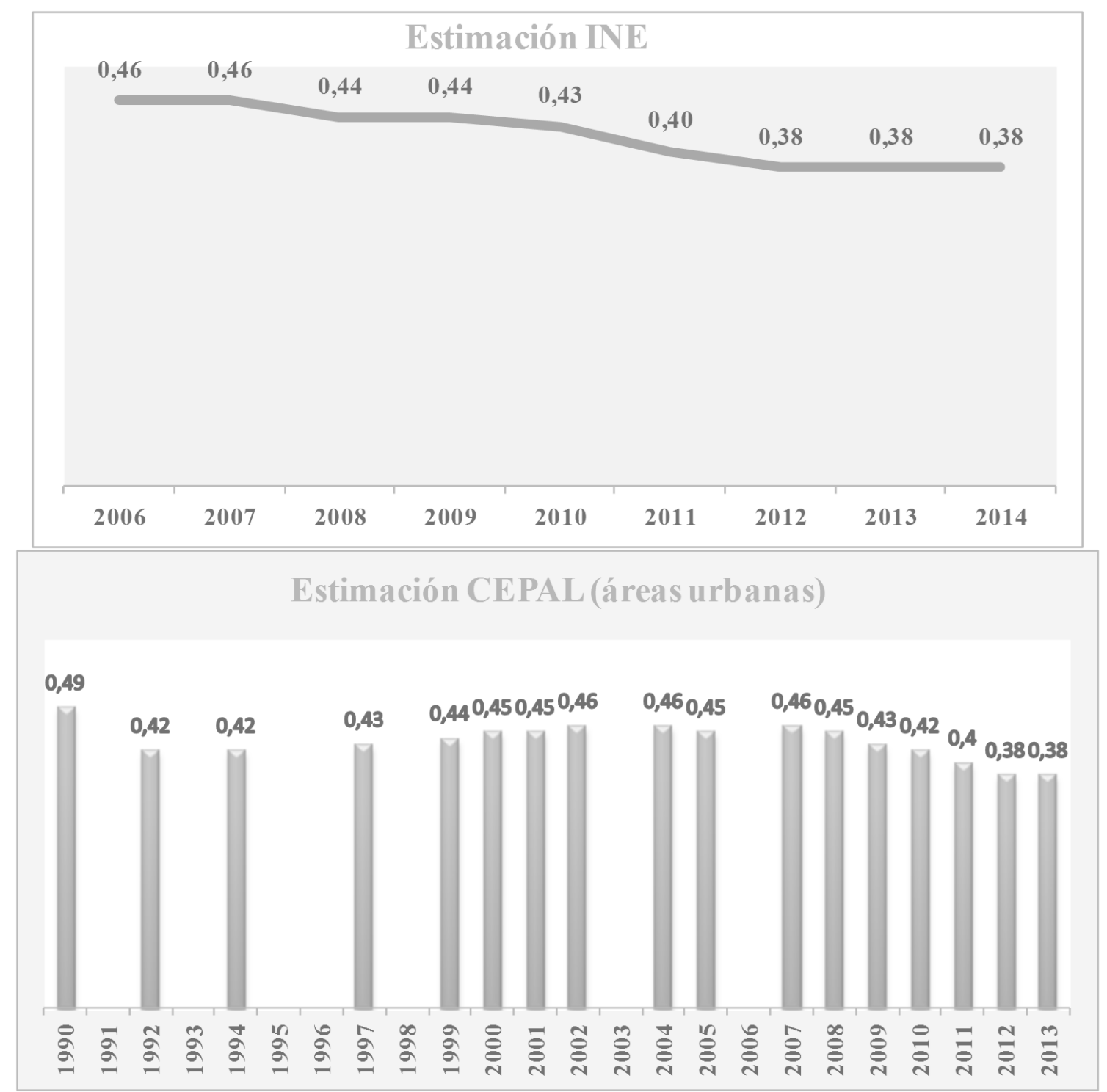

GRÁFICO 05- CONCENTRACIÓN DEL INGRESO (COEFICIENTE DE GINI) EN URUGUAY DE ACUERDO A LÍNEA INE (MET. 2006) Y CEPAL (TOTAL NACIONAL Y ÁREAS URBANAS). SERIES 2006-2014 Y 1990-2013.

Fuente: para el primer gráfico INE (2014: 40) para los datos de 1990 a 2012 e INE (2015:42) para el dato de 2013; para el segundo gráfico, elaboración propia a partir de información extraída de la base on line de CEPAL 〈http://websie.eclac.cl/infest/ajax/cepalstat.asp?carpeta=estadisticas`. 